phổi thở máy tại bệnh viện tuy chỉ đạt 89,1\% nhưng đã là khá cao.

\section{KẾT LUẬN}

Tỉ lệ tuẩn thủ thực hiện gói chăm sóc phòng ngừa VAP của nhóm Bác sỹ đạt $100 \%$ và nhóm Điều dưỡng đạt $89.1 \%$ và tỉ lệ chưa tuân thủ ở 02 bước kỹ thuật trong gói dự phòng là đặt đầu người bệnh cao $30-45^{\circ}$ và vệ sinh răng miệng lần lượt đạt 93,9\% và 95,2\%.

\section{TÀI LIÊU THAM KHẢO}

1. Bộ Y Tế, "Hướng dẫn phòng ngừa viêm phổi bệnh viện trong các cơ sở khám bênh, chữa bệnh (B̉an hành kèm theo Quyêt định số: 3671/QĐ-BYT ngày 27 tháng 9 năm 2012 của Bộ Y tê)," "Tháng 92012.

2. Đăng Thị Vân Trang (2011), "Thực hiện khảo sát mức độ tuân thủ thực hành phòng ngửa viêm phổi liên quan thở maáy tại các đơn vị săn sóc đặc biêt bênh viên Chợ Rẫy"

3. Walkey $\mathrm{Aj}^{\mathrm{j}}$ et al (2009), "Epidemiology of ventilator-associated pneumonia in a long-term acute care hospital.," Infect Control Hosp Epidemiol, pp. (4):319-24.

4 J. o. R. a. C. C. Medicine (2006), "Guidelines for the Management of Adults with Hospitalacquired, Ventilator-associated, and Healthcareassociated Pneumonia," pp. 388-416.

5 Muscedere JG et al (2010), "Mortality, attributable mortality, and clinical events as end points for clinical trials of ventilator-associated pneumonia and hospital-acquired pneumonia.," Clinical Infectious Diseases, Volume 51, p. S120S125, 01 August.

6 Drakulovic MB, (1999) Supine body position as a risk factor for nosocomial pneumonia in mechanically ventilated patients: A randomised trial. Lancet. Nov 27 1999;354(9193):1851-1858.

\title{
HộI CHỨNG HÂ̂U HUYẾT KHỐI SAU ĐIỀU TRỊ NGOẠI KHOA HUYÊT KHỐI TĨNH MẠCH SÂU CHI DƯớI CẤP TÍNH
}

\section{TÓM TẮT}

Muc tiêu: Khảo sát tỉ lệ hội chứng hậu huyết khối sau điểu trị ngoai khoa huyết khối tĩnh mach sâu chi dưới. Phương pháp: Nghiên cứu cắt ngang mô tả, đối tượng nghiên cứu là các bệnh nhân huyết khối tĩnh mạch sâu chi dưới đoạn chậu - đùi ở thời điểm 6 tháng sau khi được điều trị ngoại khoa (phẫu thuật lấy huyêt khối, can thiệp nội mạch tiêu sợi huyết) tại khoa Lông ngưoc - Mach máu Bênh viện Đại hoc Y dược Tp Hồ Chí Minh từ tháng 01/2016 đến tháng 12/2020. Kết quả: 65 bênh nhân được điều trị bằng phương pháp phẫu thuậtt (PT) mổ mở, 50 bệnh nhân được điều trị bằng can thiệp nội mạch (CTNM) bơm tiêu sợi huyết tại chố. Tuổi trung bình là 47,3 $\pm 15,0$ tuổi. Độ tuổi thường găp nhất là từ 40 - 60 tuổi chiếm tỉ lể 39,1\%. 98,3\% bệnh nhân có hình ảnh huyết khối hoàn toàn trên chụp cắt lớp vi tính. Hội chứng MayThurner chiếm tỉ lệ 68,7\%. Hội chứng hậu huyết khối sau can thiệp điều trị chiếm tỉ lệ $28,9 \%$, trong đó nhóm PT là $30,2 \%$ và nhóm CTNM là $26,5 \%$. Không ghi nhận sự khác biệt có ý nghĩa thống kê về tỉ lệ hội chứng hậu huyết khối ở 2 nhóm điêu trị với $p=0,72$. Có sự liển quan có ý nghĩa thống kê giữa thời gian khởi phát và hội chứng hậu huyết khối: $B N$ có triệu chứng khởi phát $>7$ ngày có tỉ lệ hội chứng hậu huyết khối cao hơn so với nhóm $<7$ ngày. Bệnh nhẩn có tắc

\footnotetext{
${ }^{1}$ Bệnh viện Đại học Y Dược TP.HCM

Đại hoc Y Dước TP.HCM

Chịu trách nhiệm chính: Lê Phi Long

Email: long.lp@umc.edu.vn

Ngày nhận bài: 5.4.2021

Ngày phản biện khoa học: 24.5.2021

Ngày duyệt bài: 4.6.2021
}

\section{Lê Phi Long ${ }^{1}$, Nguyễn Hoài Nam²}

nghẽn sau 6 tháng điều trị có tỷ lệ hội chứng hậu huyết khối cao hơn so với không có tổn thương tắc nghẽn. Kết luận: Hội chứng hậu huyết khối là một vấn đề cân quan tâm theo dõi sau điều trị huyết khối tĩnh mạch sâu chi dưới cấp tính.

Tư khóa: thuyên tắc tĩnh mạch sâu, hội chứng hậu huyết khối

\section{SUMMARY \\ POST-THROMBOTIC SYNDROME IN PATIENTS AFTER SURGICAL TREATMENT OF LOWER EXTRIMITY DEEP VENOUS THROMBOSIS}

Objectives: To investigate the incidence of postthrombotic syndrome in the patients after sugical treatment of lower extrimity deep venous thrombosis. Methods: Descriptive cross-sectional study in patients who had lower extremity deep vein thrombosis at iliac-femoral segment undergoing surgical treatment (open thrombectomy and endovascular intervention) after in the Thoracic and Vascular department, UMC, Ho Chi Minh City from January 2016 to December 2020. Results: 65 patients were treated with surgical thrombectomy; 50 patients were treated with endovascular intervention. The mean age was $47.3 \pm$ 15.0 years old. It was accounted for $39.1 \%$ patients in the age from 40 to 60 years old. Most of the patients had complete thrombosis on contrast-enhanced computed tomography scan (98.3\%). May-Thurner syndrome accounted for $68.7 \%$. Of $28.9 \%$ patients was confirmed with post-thrombotic syndrome after treatment. This rate in the open thrombectomy group was $30.2 \%$ and the endovascular intervention group was $26.5 \%$. There was no statistically significant difference in the rate of post-thrombotic syndrome in 
the 2 groups $(p=0.72)$. There was a statistically significant association between time to onset and post-thrombotic syndrome: patients with symptom onset $>7$ days had an increased rate of postthrombotic syndrome compared with the group $<7$ days with $p=0.004$. There is a statistically significant association between obstructive lesions and postthrombotic syndrome. $(p<0.001)$. Conclusion: Postthrombotic syndrome had been need follow-up after treatment of acute lower extremity deep vein thrombosis.

Key words: deep vein thrombosis, postthrombotic syndrome

\section{I. ĐĂT VẤN ĐỀ}

Hội chứng hậu huyết khối, là một di chứng mạn tính của huyết khối TM sâu, cũng gây ảnh hưởng nhiêu đến chất lượng sống và làm tiêu tốn rất nhiều kinh phí điều tri [1]. Một khảo sát khác của tác giả Prandoni và cộng sự trên 224 bệnh nhân huyết khối tĩnh mạch sâu, theo dõi sau 5 năm, tỷ lệ mắc hội chứng sau huyết khối là $30 \%$. Tỷ lệ thuyên tắc phối có triệu chứng trên các trường hợp bị huyết khối tĩnh mạch sâu cấp tính là khoảng $10 \%$. Tỷ lệ di chứng sau huyết khối cũng chiếm khoảng $2 / 3$ các trường hợp này [1]. Do đó, việc loại bỏ sớm huyết khối trong lòng tĩnh mạch, phục hồi sớm lưu thông máu bình thường, phối hợp với kháng đông liệu pháp, sẽ giúp ngăn chặn huyết khối tiến triển, giảm thiểu nguy cơ di chuyển huyết khối, giảm thiểu hiên tượng tái phát huyết khối, giúp bảo tồn chức năng các van tĩnh mạch. Hiện tại ở Việt Nam, các báo cáo về can thiệp điều trị lấy huyết khối hoặc dùng tiêu sợi huyết trực tiếp còn rất ít. Tỉ lê hội chứng hậu huyết khối còn chưa được ghi nhận trong các báo cáo. Chính vì vậy, chúng tôi làm nghiên cứu này nhằm xác định tỉ lệ hội chứng hậu huyết khối ở các bệnh nhận được điều trị ngoại khoa huyết khối tĩnh mạch sâu chi dưới cấp tính tại Bệnh viện Đại học Y dược Tp Hồ Chí Minh.

\section{II. ĐỐI TƯƠ'NG VÀ PHƯƠNG PHÁP NGHIÊN CỨU}

Nghiên cứu cắt ngang mô tả, đối tượng nghiên cứu là các bệnh nhân huyết khối tĩnh mạch sâu chi dưới đoạn chậu - đùi đã được phẫu thuật lấy huyết khối, can thiệp nội mạch tiêu sợi huyết theo Thời điểm khảo sát là 6 tháng sau điều trị. Hội chứng hậu huyết khối được chẩn đoán khi thang điểm Villalta $\geq 5$ điểm, hoắc có loét chân do tĩnh mach [2]

*Phân độ hội chứng hậu huyết khối [2]

+ Nhẹ: thang điểm Villalta từ $5-9$ điểm

+ Trung bình: thang điểm Villalta từ 10-14 điểm

+ Nặng: thang điểm Villalta $\geq 15$ điểm hoặc có loét chân do tĩnh mạch.

* Xử lý và phân tích số liệu: bằng phần mềm SPSS 20.0. Các biến định lượng được biểu thi bằng trung bình và độ lệch chuẩn, biển định tính được biểu thị dưới dạng tần số và tỷ lệ phần trăm. So sánh đặc điểm trước mổ giữa hai nhóm sử dụng phép kiểm chi bình phương (X2) hoặc kiểm đinh Fisher. Sử dung phép kiểm $t$ test, hay Mann-Whitney với các biến liên tuc để so sánh các trung bình. Khác biệt có ý nghĩa thống kê khi $\mathrm{p}<0.05$.

\section{KẾT QUẢ NGHIÊN CỨU}

Trong thời gian nghiên cứu từ tháng 01/2016 đến 12/2020, chúng tôi thu nhận được 115 bệnh nhân (BN) được chẩn đoán huyết khối tĩnh mạch sâu chi dưới cấp tính tầng chậu - đùi và được can thiệp điều trị tại khoa Lồng ngực - Mạch máu Bệnh viện Đại học Y Dược Tp Hồ Chí Minh, bao gồm 65 BN được phẫu thuật (PT) lấy huyết khối tĩnh mạch, có hoặc không kèm đặt giá đõ nôi mach và $50 \mathrm{BN}$ được can thiêp nôi mach (CTNM) bơm tiêu sợi huyết trực tiếp vào huyết khối, có/không kèm hút huyết khối, có/không kèm đặt giá đỡ nội mạch. Tuổi trung bình của nhóm BN nghiên cứu là $47,3 \pm 15,0$. Không có sự khác biệt có ý nghĩa thống kê về tuổi trung bình của 2 nhóm can thiệp với $p=0,53>0,05$ ( $\mathrm{t}$ test). Trong nhóm BN nghiên cứu, độ tuổi thường găp nhất là từ $40-60$ tuổi chiếm tỉ lệ $39,1 \%$. Nhóm tuổi kế tiếp thường gặp là nhóm tuổi 20 - 40 tuổi chiếm 32,2\%. Ở các nhóm can thiệp, độ tuổi thường gặp nhất cũng là từ 40 60 tuổi, lần lượt là 38,5\% ở nhóm PT lây huyết khối và $40 \%$ ở nhóm CTNM bơm TSH. Số liệu cụ thể minh họa trong bảng 1.

Bảng 1: Đặc điểm chung của nhóm nghiên cứu

\begin{tabular}{|c|c|c|c|c|}
\hline Đặc điểm & $\begin{array}{c}\text { Nhóm BN } \\
\text { nghiên cứu } \\
(\mathbf{N = 1 1 5})\end{array}$ & $\begin{array}{c}\text { Nhóm PT lấy } \\
\text { huyết khối } \\
(\mathbf{N = 6 5 )}\end{array}$ & $\begin{array}{c}\text { Nhóm CTNM bơm } \\
\text { TSH } \\
\mathbf{( N = 5 0 )}\end{array}$ & Giá trị p* \\
\hline Giới tính & $26(22,6 \%)$ & $13(20,0 \%)$ & $13(26,0 \%)$ & 0,50 \\
\hline Nam & $269(77,4 \%)$ & $52(80,0 \%)$ & $37(74,0 \%)$ & \\
\hline Nữ & $47,3 \pm 15,0$ & $48,1 \pm 15,4$ & $46,3 \pm 14,6$ & 0,53 \\
\hline Tuối (năm) & \multicolumn{3}{|l}{}
\end{tabular}


TẠP CHÍ Y HỌC VIẸTT NAM TẬP 503 - THÁNG 6 - SỐ 2 - 2021

\begin{tabular}{|c|c|c|c|c|}
\hline Nhóm tuổi & & & & 0,86 \\
\hline$<20$ & $3(2,6 \%)$ & $1(1,5 \%)$ & $2(4,0 \%)$ & \\
\hline $20-40$ & $37(32,2 \%)$ & $21(32,3 \%)$ & $16(32,0 \%)$ & \\
\hline $40-60$ & $45(39,1 \%)$ & $25(38,5 \%)$ & $20(40,0 \%)$ & \\
\hline$>=60$ & $30(26,1 \%)$ & $18(27,7 \%)$ & $12(24,0 \%)$ & \\
\hline Tiền căn huyết khối TM sâu & $11(9,6 \%)$ & $7(10,8 \%)$ & $4(8,0 \%)$ & 0,75 \\
\hline Tiền căn ung thư & $1(0,9 \%)$ & $1(1,5 \%)$ & $0(0,0 \%)$ & $>0,99$ \\
\hline Tiên căn phâu thuật & $14(12,2 \%)$ & $11(16,9 \%)$ & $3(6,0 \%)$ & 0,091 \\
\hline Tiền căn chấn thương & $5(4,3 \%)$ & $5(7,7 \%)$ & $0(0,0 \%)$ & 0,068 \\
\hline Tiền căn gia đình & $4(3,5 \%)$ & $3(4,6 \%)$ & $1(2,0 \%)$ & 0,63 \\
\hline Bất động & $8(7,0 \%)$ & $6(9,2 \%)$ & $2(4,0 \%)$ & 0,46 \\
\hline Uống thuốc ngừa thai & $20(17,4 \%)$ & $9(13,8 \%)$ & $11(22,0 \%)$ & 0,32 \\
\hline Sử dụng nội tiết tố nữ & $2(1,7 \%)$ & $1(1,5 \%)$ & $1(2,0 \%)$ & $>0,99$ \\
\hline Uं vùng chậu & $4(3,5 \%)$ & $2(3,1 \%)$ & $2(4,0 \%)$ & $>0,99$ \\
\hline Bệnh tự miền & $3(2,6 \%)$ & $2(3,1 \%)$ & $1(2,0 \%)$ & $>0,99$ \\
\hline
\end{tabular}

Hội chứng hậu huyết khối $(p=0,072)^{*}$

Nhóm CTNM bơm TSH $(n=50)$

Nhóm PT lấy huyết khối ( $n=65)$

Nhóm BN nghiên cứu ( $n=115$ )

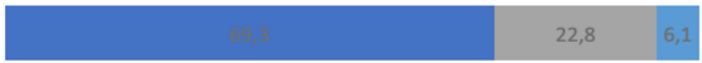

$\begin{array}{lllllllllll}0 \% & 10 \% & 20 \% & 30 \% & 40 \% & 50 \% & 60 \% & 70 \% & 80 \% & 90 \% & 100 \%\end{array}$

Biểu đồ 1: Tỉ lệ hội chứng hậu huyết khôi tại tháng thứ 6 sau can thiệp

Hội chứng hậu huyết khối sau 6 tháng điêu trị chiếm tỉ lệ 28,9\%. Nhóm PT là 30,2\% và nhóm CTNM là 26,5\%. Không ghi nhận sự khác biệt có ý nghĩa thống kê về tỉ lệ hội chứng hậu huyết khối ở 2 nhóm điều trị với $p=0,72>0,05$. Có 1 bệnh nhân tử vong ở nhóm PT lấy huyết khối, BN này tử vong ở tháng thứ 5 sau can thiệp do bệnh lý ung thư tiến triển. 1 bệnh nhân bỏ tái khám và mất theo dõi

Bảng 2: Các yếu tố liên quan đến hội chứng hậu huyêt khôi

\begin{tabular}{|c|c|c|c|}
\hline Đặc điểm & $\begin{array}{c}\text { Không HC hậu HK } \\
(\mathrm{N}=80)\end{array}$ & $\begin{array}{c}\text { HC hâau HK } \\
(\mathbf{N}=33)\end{array}$ & Giá trị p \\
\hline Nữ & $66(82,3 \%)$ & $22(66,7 \%)$ & $0,084 *$ \\
\hline Tuối (năm) & $47,8 \pm 13,9$ & $46,8 \pm 17,6$ & $0,77^{* *}$ \\
\hline Thời gian khởi phát (ngày) & $5,9 \pm 3,7$ & $8,3 \pm 4,3$ & $0,006 * *$ \\
\hline Ngày khởi phát bệnh & & & $0,004 *$ \\
\hline$<=7$ ngày & $61(75,9 \%)$ & $15(45,5 \%)$ & \\
\hline$>7$ ngày & $19(24,1 \%)$ & $18(54,5 \%)$ & \\
\hline Phương pháp điều trị & & & 0,68 \\
\hline Phấu thuật lấy HK & $44(55,0 \%)$ & $20(60,6 \%)$ & \\
\hline CTNM bơm TSH & $36(45,0 \%)$ & $13(39,4 \%)$ & \\
\hline Tốn thương sau 6 tháng & & & $<0,001$ \\
\hline Không hẹp tắc & $66(82,3 \%)$ & $4(12,1 \%)$ & \\
\hline Hẹp lòng mạch & $12(15,2 \%)$ & $10(30,3 \%)$ & \\
\hline Tắc nghẽn hoàn toàn & $1(1,3 \%)$ & $19(57,6 \%)$ & \\
\hline Không đánh giá được & $1(1,3 \%)$ & $(0 \%)$ & \\
\hline
\end{tabular}


Không ghi nhận sự khác biệt có ý nghĩa thống kê về tỉ lệ hội chứng hậu huyết khối ở 2 nhóm điều trị với $p=0,72>0,05$. Không ghi nhận có sự liên quan hội chứng hậu huyết khối với các yếu tố: tuổi, giới, yễu tổ đông máu, phương pháp can thiệp, tỉ lệ biến chứng. Có sự liên quan có ý nghĩa thống kê giữa thời gian khởi phát và hội chứng hậu huyết khối. BN có triệu chứng khởi phát $>7$ ngày có tỉ lệ hội chứng hậu huyết khối tăng hơn so với nhóm < 7ngày với $\mathrm{p}=$ $0,004<0,05$. Có sự liên quan có ý nghĩa thống kê giữa tổn thương tắc nghẽn và hội chứng hậu huyết khối. BN có tắc nghẽn sau 6 tháng điều trị có tỷ lệ hội chứng hậu huyết khối cao hơn so với BN khồng có tổn thương tắc nghẽn. $(p<0,001)$

\section{BÀN LUÂN}

Không có tiêu chuẩn vàng nào để chẩn đoán hội chứng hậu huyết khối. Hội chứng hậu huyết khối nên được đánh giá ở bệnh nhân có HKTM sâu và tiếp tục có triệu chứng ở chi cùng bên sau nhiều tháng [3]. Gần đây, các chuyên gia về mạch máu đã khuyến cáo nên sử dụng thang điểm Villalta nhằm chẩn đoán cũng như phân loại mức độ nghiêm trọng của bệnh. Trong nghiên cứu của tác giả Chan Park ghi nhận thang điểm Villalta ở nhóm được dùng giá đõ̃ nội mạch kèm theo tiêu sợi huyết trực tiếp qua can thiệp nội mạch thấp hơn nhóm không sử dụng giá đỡ nội mạch, sự khác biệt không có ý nghĩa thống kê [3].

Hội chứng hậu huyết khối là một di chứng khá thường gặp và ảnh hưởng nhiều đến chất lượng sống của người bệnh, sau khi huyết khối TM sâu diển tiến dần sang giai đoạn mạn tính. Tỷ lệ mắc hậu huyết khối xuất hiện đến $30 \%$ các trường hợp huyết khối TM sâu trong vòng năm đầu [4], và sẽ tăng lên nếu có kèm theo các yếu tố thúc đẩy như béo phì, bệnh tăng đông tiềm ẩn, tái phát huyết khối chân cùng bên, sử dụng kháng đông không đầy đủ và có đặt lưới lọc TM chủ dưới [5].

Loét chân khó lành trong hội chứng hậu huyết khối là một biểu hiện ở giai đoạn trễ của tình trang suy tĩnh mạch thứ phát hậu huyết khối, khi các van tĩnh mạch hư hỏng toàn bộ, ứ trệ máu kéo dài dẫn đển loạn dưỡng nặng và mất mô. Loét chân hậu huyết khối chiếm đến $40 \%$ các trường hợp loét liên quan đến bệnh TM mạn tính chi dưới [6].

Thử nghiệm lâm sàng CaVenT năm 2012 trên 209 bênh nhân được điều trị huyết khối TM sâu chi dưới, theo dõi kết quả dài hạn với hội chứng sau huyết khối là kết quả nguyên phát. Sau 2 năm, CNTM bơm TSH giảm thiểu nguy cơ mắc hội chứng từ $55.6 \%$ xuống $41.1 \%(p=0.047)$. Sau 5 năm, nguy cơ được giảm đến $28 \%$ (từ $71 \%$ xuống $43 \%, p<0.001)$, [7].

Trong nghiên cứu của chúng tôi, tỉ lệ bệnh nhân có Villalta < 5 điểm ở nhóm phẫu thuật thấp hơn nhóm TSH (68.8\% và $74 \%)$, không có sự khác biệt về mặt thống kê giữa hai nhóm trong từng thang điểm. Tỉ lệ này tương đối thấp hơn so với các kết quả đã được đưa ra trước đây.

Nghiên cứu của tác giả Ignatyev trên 65 bệnh nhân có huyết khối TM chậu - đùi từ năm 2012 đến năm 2018 ghi nhân thang điểm Villalta sau thời gian theo dỗi dài hạn ở nhóm phẫu thuật và nhóm dùng kháng đông như sau: không có (0-4 điểm) $83.3 \%$ và $12.5 \%$, trung bình (5-9 điểm) $5.6 \%$ và $29.2 \%$, nặng (10-14 điểm) $11.1 \%$ và $41.6 \%$, nghiêm trọng ( $>14$ điểm) 0 và $16.7 \%$. $(p<0.001)$ [8].

\section{KẾT LUÂ̂N}

Hội chứng hậu huyết khối là một vấn đề cần quan tâm theo dõi sau điều trị can thiệp huyết khối tĩnh mạch sâu chi dưới cấp tính. Tỉ lệ mắc phải huyết khối tĩnh mạch sâu sau 6 tháng là $28,9 \%$.

\section{TÀI LIỆ THAM KHẢO}

1. Prandoni $P$, Lensing A (1996), "The long term clinical course of acute deep venous thrombosis", Ann Intern Med, p125.

2. Kahn S.R., Partch H., Vedantham S., et al (2009), "Definition of post-thrombitic syndrome of the leg for use in clinical investigations: a recommendation for standardization", Journal of thrombosi and haemostasis, 7, p.879-883

3. Park C, So BJ (2015). "Long-Term Results of Catheter-Directed Thrombolysis Combined with Iliac Vein Stenting for Iliofemoral Deep Vein Thrombosis". Vasc Specialist Int., 31(2): 47-53. doi: 10.5758/vsi.2015.31.2.47.

4. Patrick H. Carpenter, Peter Gloviczki (2017), "Outcome assessment in acute venous disease", Handbook of Venous disorders, 4th edition pp.763

5. Kahn S.R, Kearon C, Julian JA, et al (2005), "Predictors of the postthrombotic syndrome during long-term treatment of proximal deep vein thrombosis", J. Thromb Haemost, pp.718-23.

6. Cornwall JV, Doré CJ, Lewis JD (1986), "Leg ulcers: Epidemiology and aetiology", Br. J. Surg, pp.693-6

7. Hölper $\mathbf{P}$, Kotelis D, Attigah N, Hyhlik-Dürr A, et al (2010), "Longterm results after surgical thrombectomy and simultaneous stenting for symptomatic iliofemoral venous thrombosis". Eur ] Vasc Endovasc Surg. 39(3): 349-55. doi: 10.1016/j.ejvs.2009.09.028. Epub 2010 Jan 8. PMID: 20060755

8. Ignatyev IM (2020). "Surgical Thrombectomy for Treatment of Acute Iliofemoral Venous Thrombosis". Austin J Surg. 7(1): 1242. 